\title{
Dimethylarginine dimethylaminohydrolase I enhances tumour growth and angiogenesis
}

\section{Kostourou', SP Robinson', JE Cartwright' and GStJ Whitley*,I}

'Department of Biochemistry and Immunology, St George's Hospital Medical School, London SWI7 ORE, UK

Angiogenesis is a prerequisite for tumour progression and is highly regulated by growth factors and cytokines a number of which also stimulate the production of nitric oxide. Asymmetric dimethylarginine is an endogenous inhibitor of nitric oxide synthesis. Asymmetric dimethylarginine is metabolised by dimethylarginine dimethylaminohydrolase. To study the effect of dimethylarginine dimethylaminohydrolase on tumour growth and vascular development, the rat C6 glioma cell line was manipulated to overexpress the rat gene for dimethylarginine dimethylaminohydrolase I. Enhanced expression of dimethylarginine dimethylaminohydrolase I increased nitric oxide synthesis (as indicated by a two-fold increase in the production of cGMP), expression and secretion of vascular endothelial cell growth factor, and induced angiogenesis in vitro. Tumours derived from these cells grew more rapidly in vivo than cells with normal dimethylarginine dimethylaminohydrolase I expression. Immunohistochemical and magnetic resonance imaging measurements were consistent with increased tumour vascular development. Furthermore, dimethylarginine dimethylaminohydrolase activity was detected in a series of human tumours. This data demonstrates that dimethylarginine dimethylaminohydrolase plays a pivotal role in tumour growth and the development of the tumour vasculature by regulating the concentration of nitric oxide and altering vascular endothelial cell growth factor production.

British Journal of Cancer (2002) 87, 673-680. doi:10.1038/sj.bjc.66005I8 www.bjcancer.com

(C) 2002 Cancer Research UK

Keywords: dimethylarginine dimethylaminohydrolase; nitric oxide; nitric oxide synthase; vascular endothelial growth factor; asymmetric dimethylarginine

Angiogenesis is the formation of new capillaries from existing blood vessels. It is a multistep process that involves dissociation of endothelial cells (EC) from adjacent pericytes, remodelling of the extracellular matrix, proliferation and migration of EC and capillary differentiation. Insight into the regulation of this process is central to our understanding of a number of biological processes whether physiological, as occurs during development, the reproductive cycle and wound healing, or pathological, as occurs during atherogenesis, diabetic retinopathy and tumour progression (Carmeliet and Jain, 2000; Folkman, 1995).

There is strong evidence to suggest that nitric oxide (NO), produced from arginine by the nitric oxide synthases (NOS), is a crucial signalling molecule and regulator of angiogenesis (Chinje and Stratford, 1997). NO enhances vascular permeability, induces extracellular matrix degradation, endothelial cell proliferation and migration (Ziche et al, 1994; Trachtman et al, 1996; Fukumura et al, 1997) and stimulates the expression of vascular endothelial growth factor (VEGF) while also mediating many of its angiogenic effects (Chin et al, 1997; Papapetropoulos et al, 1997). The role of $\mathrm{NO}$ in tumour progression is still unclear, since NO has been shown to inhibit angiogenesis (Pipili-Synetos et al, 1995) and NO produced by activated macrophages can be cytotoxic to tumour cells (Stuehr and Nathan, 1989). However, NO has been positively correlated with tumour grade in human gynaecological, breast, neuronal, and head and neck tumours (Thomsen et al, 1994; Cobbs et al, 1995; Gallo et al, 1998; Reveneau et al, 1999).

*Correspondence: Dr G Whitley; E-mail: g.whitley@sghms.ac.uk Received 5 February 2002; revised 5 April 2002; accepted 26 June 2002
Regulation of NO production may therefore play an important role in the regulation of angiogenesis and consequently tumour progression. Methylated analogues of arginine such as asymmetric dimethylarginine (ADMA) and N-mono methylarginine (L-NMMA) are competitive inhibitors of NO synthesis. Free ADMA is found in plasma and urine of healthy individuals and is synthesised by the post-translational methylation of protein arginine residues and liberated upon their hydrolysis (Kakimoto and Akazawa, 1970; Fickling et al, 1993). The intracellular concentration of ADMA reaches levels sufficient to inhibit NO synthesis (Macallister et al, 1994) and can be modulated by changes in the activity of the enzyme dimethylarginine dimethylaminohydrolase (DDAH) (Ogawa et al, 1989; Macallister et al, 1996).

Two isoforms of DDAH have been reported (Leiper et al, 1999). DDAH I predominates in tissues that express the neuronal isoform of NOS, while DDAH II distribution mainly follows endothelial NOS (Leiper et al, 1999). Dysfunction of DDAH and elevated levels of its substrate ADMA have been implicated in pathological conditions including hypertension, pre-eclampsia, renal failure and atherosclerosis (Matsuoka et al, 1997; Holden et al, 1998; Miyazaki et al, 1999). Recently, high levels of ADMA have been correlated with impaired angiogenesis in hypercholesterolemic mice (Jang et $a l, 2000)$. The aim of our study was to test the hypothesis that tumour-derived ADMA plays a significant role in the regulation of tumour growth and vascular development. We demonstrate that increased DDAH expression results in decreased tumour ADMA, increased NO production, tumour growth and angiogenesis, and that these effects are mediated through changes in the expression of VEGF. We also show preliminary evidence of DDAH activity in human tumours. 


\section{METHODS}

\section{Cell culture and transfections}

Rat C6 glioma cells (European Collection of Cell Cultures, Centre for Applied Microbiology and Research, UK) were maintained in Ham's F-10 medium containing $5 \mathrm{mM} \mathrm{L-glutamine,} 100 \mathrm{U} \mathrm{ml}^{-1}$ penicillin, $0.1 \mathrm{mg} \mathrm{ml}^{-1}$ streptomycin and $10 \%\left(\mathrm{v} \mathrm{v}^{-1}\right)$ foetal calf serum. The full length rat DDAH I cDNA was generated by RT-PCR using mRNA isolated from C6 cells, forward primer: GGAGCAAGCTTCGCCACCATGGCCGGCCTCAGCCA and reverse primer: GCCTGCTCGAGTCAAGAGTCTGTCTTCTTGTTAAT and subsequently cloned into HindIII/XhoI sites in pcDNA 3.1/hygro (InVitrogen). C6 cells were transfected using the poly L-ornithine method $\left(5 \times 10^{6}\right.$ cells per $9 \mathrm{~cm}$ plate; $10 \mu \mathrm{g}$ DNA plasmid; $10 \mu \mathrm{g} \mathrm{ml}^{-1}$ poly L-ornithine) and selected in medium supplemented with $500 \mu \mathrm{g} \mathrm{ml}^{-1}$ hygromycin B (Dong et al, 1994).

\section{Animals and tumours}

Female (7-8 weeks old) MF1/nu mice were injected subcutaneously in the flanks with $2 \times 10^{6}$ cells in $0.1 \mathrm{ml}$ PBS. Tumour growth was measured at daily intervals after anaesthetising with fluothane in $2 \% \mathrm{~N}_{2} \mathrm{O}, 5 \% \mathrm{O}_{2}$. The tumour volume was calculated using the formula: tumour volume $=\pi / 6 \cdot($ length $\times$ width $\times$ depth $)$. All procedures were performed in accordance to the Home Office Scientific Procedures Act 1986.

\section{Western blot analysis}

The protein concentration of cell lysates and tumour homogenates were determined by Bradford assay and equal amounts analysed by SDS-PAGE. DDAH expression was detected using a monoclonal antibody against rat DDAH I (Kimoto et al, 1995).

\section{DDAH activity assay}

Cells were seeded on 24 -well plates at a density of $1.5 \times 10^{5}$ cells per well and incubated in HEPES buffered Krebs solution containing $\left[{ }^{14} \mathrm{C}\right]$ L-NMMA $\left(0.8 \mu \mathrm{Ci} \mathrm{m}{ }^{-1}\right.$, specific activity $56 \mathrm{mCi}$ $\mathrm{mMol}^{-1}$ ) for $1 \mathrm{~h}$ at $37^{\circ} \mathrm{C}$. Cells were washed twice in ice-cold Krebs solution and lysed in $0.1 \%\left(\mathrm{w} \mathrm{v}^{-1}\right)$ SDS. Human tumour biopsy specimens taken during surgical removal of the tumour, or mouse tumour tissues were homogenised in $10 \mathrm{~mm}$ sodium phosphate buffer $\mathrm{pH} 6.6$ using a motor homogeniser. Aliquots of $500 \mu \mathrm{l}$ were incubated with $\left[{ }^{14} \mathrm{C}\right] \mathrm{L}-\mathrm{NMMA}\left(0.4 \mu \mathrm{Ci} \mathrm{ml}{ }^{-1}\right)$ for $1 \mathrm{~h}$ at $37^{\circ} \mathrm{C}$. The formation of $\left[{ }^{14} \mathrm{C}\right]$ citrulline was determined as previously described (MacAllister et al, 1996). The enzymatic activity was corrected for the protein concentration.

\section{HPLC analysis}

Assessment of the concentration of ADMA in tumour homogenates and in culture medium was performed as previously described (MacAllister et al, 1994).

\section{cGMP assay}

Estimation of the production of cGMP in tumour cells was performed as previously described (Whitley, 1994).

\section{In vitro assay of endothelial cell migration}

A human endothelial cell line SGHEC-7 derived from SV40 transfected human umbilical vein endothelial cells (Fickling et al, 1992) was cultivated on microcarrier (MC) beads for 2 days and embedded in fibrin gels (Nehls and Drenckhahn, 1995). Conditioned medium from confluent cultures mixed $1: 1$ with fresh medium was added. After 2 days incubation, digital images were acquired and the extent of migration was determined using Image Pro-Plus software (Media Cybernetics). Invasion was determined as the maximum length of invasive processes minus the radius of the bead.

\section{Northern blot analysis}

Total RNA was prepared from cells using TRIZOL (Gibco BRL). The probe for VEGF was a $540 \mathrm{bp}$ BamHI-HindIII fragment of the human $\mathrm{VEGF}_{121} \mathrm{cDNA}$ (nt 565-1012). The high identity in the cDNA sequences of human and rat or mouse VEGF ensures the crossreactivity of the probe (Shima et al, 1996). The probe for the $18 \mathrm{~S}$ subunit corresponds to nucleotides 552-1429 nt of the human $18 \mathrm{~S}$ gene.

\section{VEGF ELISA}

Culture medium was collected from confluent 6-well plates and analysed for VEGF expression using a murine VEGF ELISA kit ( $R \& D$ Systems, detection limit $3 \mathrm{pg} \mathrm{ml}^{-1}$ ). Tumours were excised at an early stage of development (day 15), weighed, cut in small pieces and maintained in culture medium for 4 days. VEGF secretion was measured in the culture medium. Values were correlated with the protein concentration of cells or the weight of tumours, respectively.

\section{Magnetic resonance imaging (MRI)}

A separate cohort of size-matched D27 and C6 wild type tumours were imaged at 18 and 23 days post-passage respectively. ${ }^{1} \mathrm{H}$ MR imaging was performed on a Varian spectrometer at $4.7 \mathrm{~T}$ using a two-turn surface coil ( $1 \mathrm{~cm}$ diameter $)$. Mice bearing tumours derived from D27 (mean volume $1.23 \pm 0.2 \mathrm{~cm}^{3}, n=8$ ) or C6 (mean volume $1.25 \pm 0.2 \mathrm{~cm}^{3}, n=8$ ) wild type cells were anaesthetised with a single intraperitonal dose of $10 \mathrm{ml} \mathrm{kg}^{-1}$ Hypnorm/Hypnovel and placed so the tumour hung into the centre of the surface coil. The mouse core temperature was maintained at $37^{\circ} \mathrm{C}$ by a warm water blanket. Multi-gradient echo (MGRE) images were acquired from three transverse $1 \mathrm{~mm}$ thick slices through the centre of the tumour. The readout gradient was oscillated to generate a series of eight echoes, utilising a repetition time of $100 \mathrm{~ms}$, initial echo of $5 \mathrm{~ms}$ and an echo spacing of $5 \mathrm{~ms}$, resulting in sets of images with decreased $\mathrm{R}_{2}{ }^{*}$ weighting. Tumour $\mathrm{R}_{2}{ }^{*}$ maps for each slice were generated using all eight gradient-echo image sets by fitting an exponential model on a pixel-by-pixel basis (Robinson et al, 2001; Griffiths et al, 2002). For each slice, $\mathrm{R}_{2}{ }^{*}$ was determined from a region-of-interest (ROI) encompassing the whole tumour but excluding the surrounding skin/muscle.

\section{Fluorescence microscopy}

Mice from the same cohort as used for the MRI and bearing similarly size-matched tumours were injected intravenously with $15 \mathrm{mg} \mathrm{kg}^{-1}$ of the perfusion marker Hoechst 33342 (Sigma) $1 \mathrm{~min}$ prior to cervical dislocation. Tumours were rapidly excised, frozen and sections cut $(10 \mu \mathrm{m})$. Acetone fixed sections were visualised by fluorescence microscopy. Fluorescence signals from entire tumour sections were recorded with digital images acquired under identical conditions. The area of tumour stained by Hoechst 33342 as a percentage of the total area of tumour section was calculated using anaLYSIS (Soft Image Analysis).

\section{Ethics}

Local Ethical Committee approval was obtained for the collection of human tissues. 
A

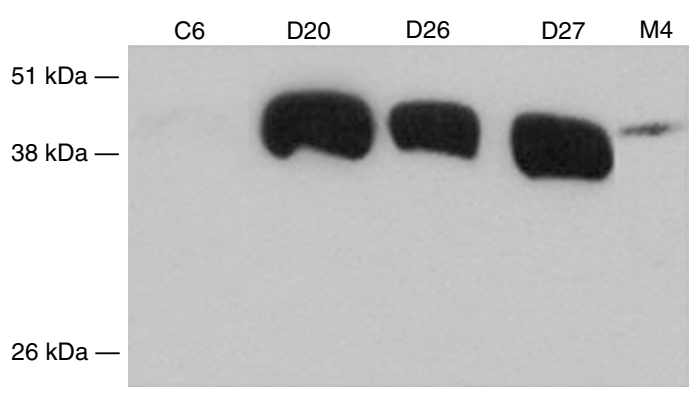

B

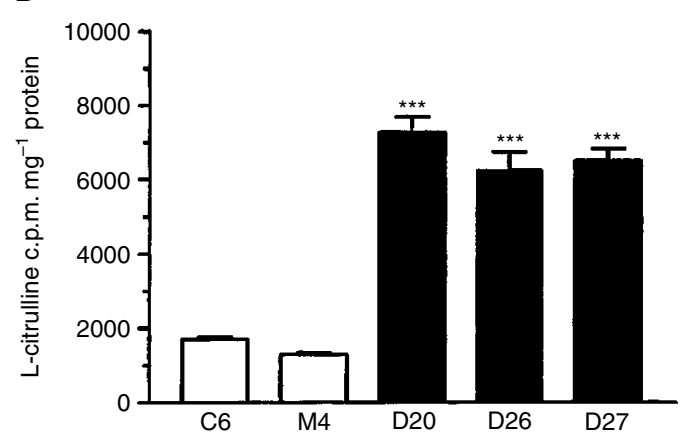

C

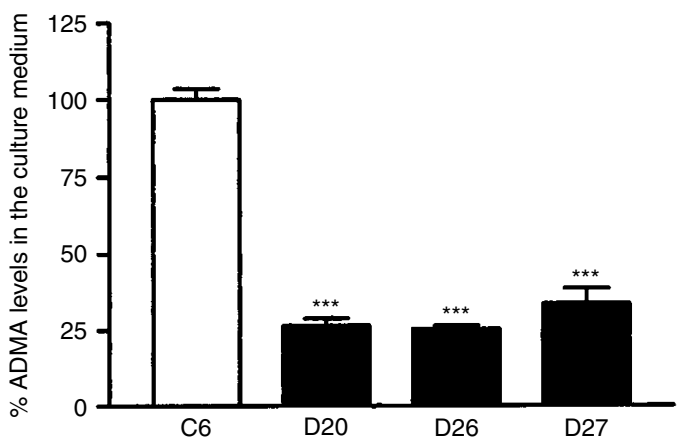

D

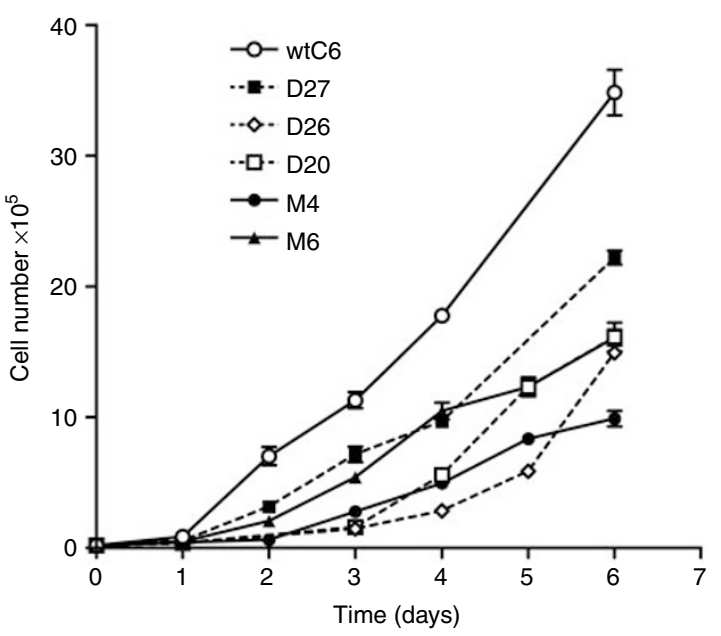

Figure I Characterisation of the stable DDAH I transfected cell lines in vitro. (A) Western blot analysis of DDAH I overexpressing cell lines $(20 \mu \mathrm{g}$ protein per lane). An increase in a band at approximately $38 \mathrm{kDa}$, indicating

\section{RESULTS}

\section{Overexpression DDAH in C6 glioma cells}

To study the role of DDAH in tumour biology, the rat C6 glioma cell line was transfected with the pcDNA vector, containing the coding region of the rat DDAH I gene. Three stable clones, (D20, D26, D27) that constitutively express DDAH I and mock transfected clones ( $\mathrm{M}$ lines, transfected with the empty vector as control) were analysed. Western blot analysis of D20, D26 and D27 cells revealed similarly high levels of DDAH I protein expression (Figure 1A). Consistent with the high protein expression these cell lines displayed, on average, a four-fold increase in enzymatic activity compared to wild type C6 and control transfected M4 cells, as determined by the conversion of ${ }^{14} \mathrm{C}$ radiolabelled L-NMMA to L-citrulline (Figure $1 \mathrm{~B}$ ). Since the function of DDAH is to catabolise the endogenous inhibitors of NO, ADMA and L-NMMA, the levels of ADMA in the culture medium of the overexpressing cell lines was examined. Overexpression of DDAH I was shown to reduce the levels of ADMA by 70-75\% (Figure 1C). Consistent with the role of ADMA as an inhibitor of NO, the decreased levels of ADMA led to an increase in NO production as indicated by a two-fold increase in the production of cGMP (C6: 12.33 \pm 1.4 , D27: $26.67 \pm 1.5$, mean \pm s.e.mean). In vitro studies showed no apparent correlation between transfection with DDAH (compared to empty vector) and growth (Figure 1D). However transfected cells generally showed slower growth rates than C6 wild type cells. All three DDAH I overexpressing cell lines grew similarly to M4 and M6 (Figure 1D) and other mock transfected lines (data not shown).

\section{Effect of DDAH I overexpression on tumour growth in vivo}

In contrast, when D26 and D27 cells were implanted into the flanks of nude mice their growth rate increased (doubling time: $\sim 2$ days) compared to the wild type or the control M4 cells (doubling time: $\sim 4$ days, Figure $2 \mathrm{~A}$ ). In a limited number of experiments the growth of C6 tumours was allowed to continue until day 26 when they reached a similar size to that of D27 at 20 days (data not shown). Western blot analysis of tumours demonstrated higher DDAH I protein expression in D27 compared to C6 tumours (Figure 2B). Homogenates from D26 and D27 tumours displayed a 2.5 -fold increase in DDAH activity (Figure 2C). The concentration of ADMA also decreased from $2.6 \mu \mathrm{g} \mathrm{mg}^{-1}$ protein in C6 tumours to undetectable levels in D27 tumours.

\section{Effect of DDAH I on tumour vascular development}

Non-invasive Magnetic Resonance Imaging (MRI) was employed to assess the blood vessel development in vivo. Deoxyhaemoglobin is paramagnetic and creates magnetic susceptibility perturbations around blood vessels, increasing the MRI transverse relaxation time $\mathrm{R}_{2}{ }^{*}$. Multi-gradient recalled echo (MGRE) MR images allow the

the presence of DDAH I was observed. (B) Assessment of DDAH activity in cell lysates by the conversion of $\left[{ }^{14} \mathrm{C}\right] \mathrm{L}$-NMMA to L-citrulline revealed that the D20, D26 and D27 cell lines had a four-fold increase in DDAH enzymatic activity. Results are means+s.e.m. of triplicates of three separate experiments (*** $P<0.00$ I compared to control, Student's $t$-test). (C) Overexpression of DDAH I reduced the concentration of ADMA by $70-75 \%$ in the culture medium as determined by HPLC analysis. Results are mean \%+s.e.m. of triplicate determinations from three separate experiments (**** $P<0.00 \mathrm{I}$, Student's $t$-test). (D) The in vitro growth rate of DDAH transfected cells (dashed lines) D20, D26, D27, mock transfected cells (solid lines) M4, M6 and wild type C6 cells is shown. Results are means \pm s.e.m. of three experiments performed in at least duplicate. 
relaxation rate $\mathrm{R}_{2}^{*}$ to be quantified, which is directly proportional to the tissue content of deoxyhaemoglobin and hence a sensitive index of tissue vascularity (Robinson et al, 2001; Griffiths et al, 2002). The average $R_{2}^{*}$ of $D 27$ and C6 tumours was $65.6 \pm 5 \mathrm{~s}^{-1}$
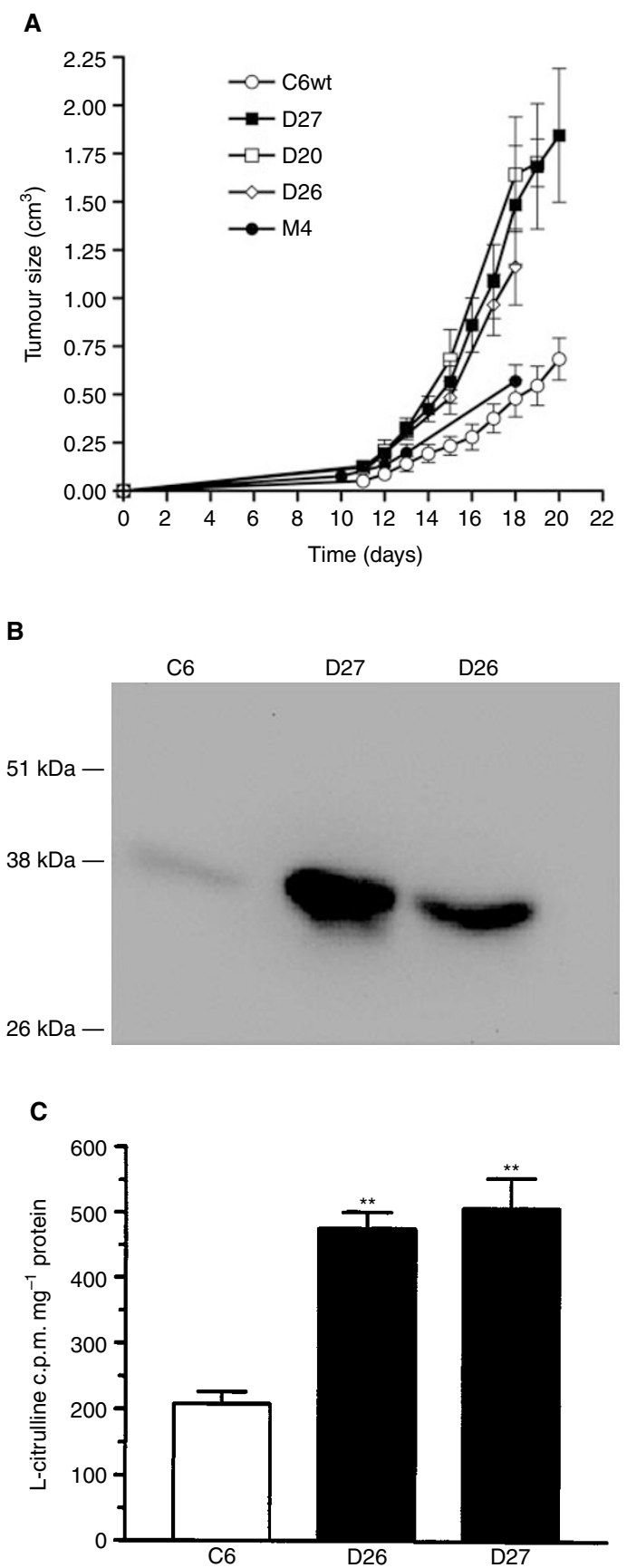

Figure 2 Overexpression of DDAH I increases the in vivo tumour growth rate. (A) In vivo, overexpression of DDAH I caused an increase in the growth rate of D20, D26 and D27 tumours compared to M4 and C6 tumours. Results are means +s.e.m. of at least two different inoculations of six mice. (B) Western blot analysis of tumours ( $100 \mu \mathrm{g}$ protein per lane) confirmed that the overexpressing DDAH tumours had higher amounts of DDAHI protein in vivo. (C) Assessment of DDAH activity in tumour homogenates by the conversion of $\left[{ }^{14} \mathrm{C}\right] \mathrm{L}-\mathrm{NMMA}$ to L-citrulline. Tumour homogenates derived from D26 and D27 revealed a two- and a half-fold increase in their DDAH activity compared to $\mathrm{C} 6$ tumours. Results are means+s.e.m. of duplicates from two separate experiments (**P $<0.02$ compared to control, Student's t-test). and $42.5 \pm 4 \mathrm{~s}^{-1}$ respectively. The significantly faster $\mathrm{R}_{2}^{*}$ displayed by the D27 tumours compared to the wild type (Student's $t$-test, $P<0.001)$ indicates a higher concentration of deoxyhaemoglobin and increased tumour vascularisation (Figure 3A). In addition to the higher growth rate, tumours derived from the D27 cells were shown upon excision to bleed profusely and to be more vascularised compared to wild type tumours (Figure 3B).

\section{DDAH I expression results in increased tumour perfusion}

The effect of DDAH I on tumour perfusion was examined using the fluorescent marker Hoechst 33342 (Smith et al, 1988). This is a nuclear dye that, upon injection, stains endothelial cells and cells immediately adjacent to tumour blood vessels. Since the time of experiment was limited to $1 \mathrm{~min}$ to avoid diffusion of the dye, Hoechst 33342 marked only the functionally perfused vessels. Fluorescence microscopy showed that the extent of the staining is greater in D27 tumours compared to wild type tumours indicating better tumour perfusion and increased number of functional vessels (C6: $5.1 \% \pm 0.5, \mathrm{D} 27$ : $9 \% \pm 0.5$, mean \pm s.e.m, $n=4$ ).

\section{DDAH I induces in vitro vascular endothelial cell migration}

The role of DDAH I on vessel development was examined further using an in vitro assay of endothelial migration. Human endothelial cells, SGHEC-7, grown on microcarrier (MC) beads and embedded in fibrin gels were incubated with conditioned medium from confluent cultures of C6, D27 or SGHEC-7 cells and the formation of invasive processes was analysed over a period of 2 days. Invasion of endothelial cells into the fibrin gel was used as an indicator of the angiogenic potential of factors produced by the D27 cells. The average of the maximum length of the process minus the

\section{A}
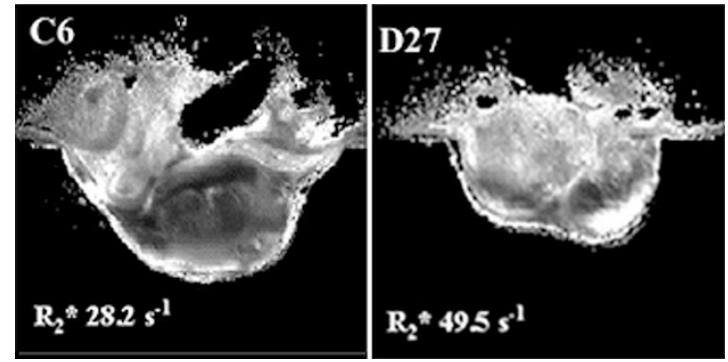

B
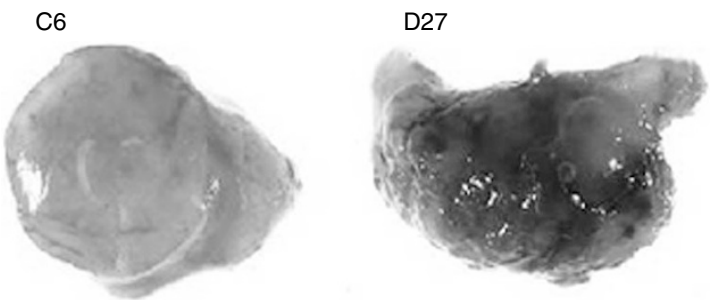

Figure 3 Overexpression of DDAH I affects the tumour vasculature (A) Representative $\mathrm{R}_{2} *$ maps obtained from size-matched C6 and D27 tumours, and their associated average $R_{2} *$ relaxation rates, imaged 23 days and 18 days post-passage respectively. The more intense $R_{2} *$ map (brighter image) of the D27 tumour is consistent with a high concentration of deoxyhaemoglobin and hence better vessel development. (B) Representative photographs of size-matched tumours derived from C6 and D27 cells. C6 and D27 tumours were excised 26 and 20 days post-implantation respectively. DDAH I overexpressing tumours are better vascularised compared to wild type or control tumours. 
radius of the bead from $40 \mathrm{MC}$ beads was determined. Statistical analysis showed that conditioned medium from D27 cells significantly stimulated the migration of SGHEC-7 cells into the fibrin gel compared to medium from C6 or SGHEC-7 cells (Figure 4).

\section{DDAH I expression increases the production of VEGF}

Since it has previously been suggested that NO can mediate some of the angiogenic effects of VEGF, we examined whether the effects of DDAH and ADMA on tumour angiogenesis were mediated through changes in VEGF. In vitro analysis of VEGF mRNA displayed a two-fold increase in D20, D26, D27 compared to control M4 and wild type C6 cells as determined by Northern blot analysis (Figure 5A). This correlated with an average two-fold increase in VEGF secretion in the culture medium as determined by ELISA (Figure 5B). Ex vivo analysis of VEGF secretion displayed a two-fold increase in D27 compared to C6 tumour culture supernatant (Figure 5C).

\section{DDAH I activity in human tumours}

DDAH activity was detected in eight human tumours, including those from the brain (Figure 6).

\section{DISCUSSION}

Tumour angiogenesis is driven by the requirement of the tumour for nutrients and oxygen. Angiogenesis involves the coordination of a number of independent events including the production of proteases and angiogenic factors that have both a chemotactic and mitogenic effect on endothelial cells. We demonstrate a novel mechanism by which a reduction in tumour ADMA, as a result of increased DDAH activity, stimulates tumour growth and angiogenesis through increased NO and VEGF expression.

Regulation of the production of NO through DDAH activity is important since NO can have pleiotropic effects on diverse aspects of tumour biology. There is positive correlation between NOS activity and tumour grade in human breast, gynaecological, head, neck and neuronal tumours (Thomsen et al, 1994; Cobbs et al, 1995; Gallo et al, 1998; Reveneau et al, 1999) and NOS inhibitors have been shown to decrease tumour growth (Thomsen et al,

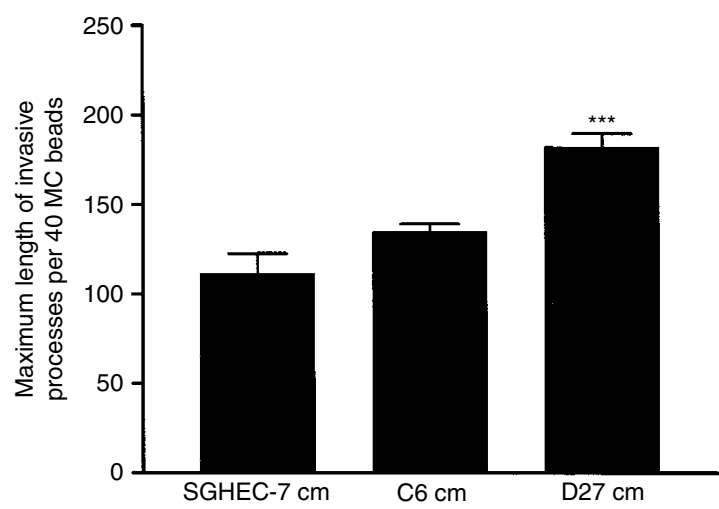

Figure 4 Conditioned medium from DDAH I overexpressing cells induces endothelial cell migration in vitro. A human endothelial cell line SGHEC-7 was grown on beads in three dimensional fibrin gels and incubated with conditioned medium $(\mathrm{cm})$ from confluent SGHEC-7, D27 or C6 cells. Quantitative analysis of invasive process formation was expressed as the average of the maximum length of process minus the radius of the bead per $40 \mathrm{MC}$ beads. Results are means+s.e.m. of 40 individual measurements in three separate experiments (*** $P<0.00$ I compared to control, Student's t-test).
A

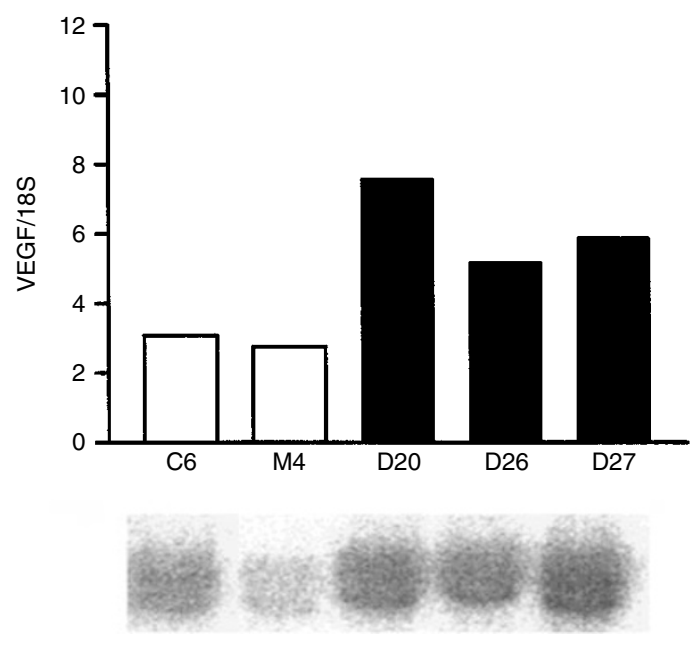

B

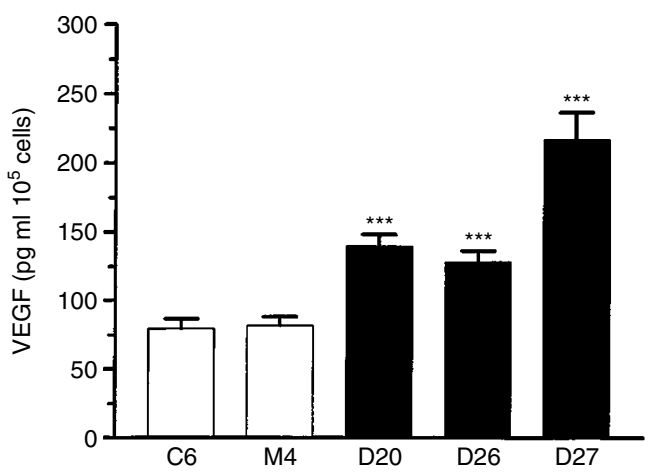

C

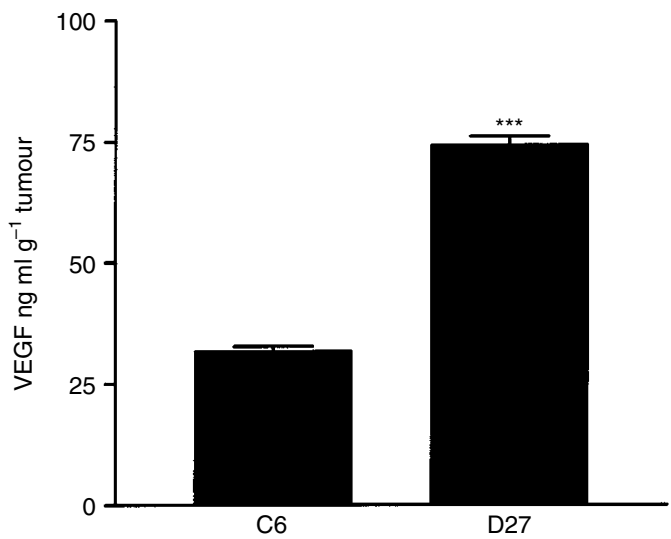

Figure 5 Overexpression of DDAH I results in upregulation of VEGF. (A) VEGF mRNA expression in the D27, D26, D20, M4 and parent C6 cell lines assessed by Northern blot analysis. RNA loading was corrected according to the levels of the $18 \mathrm{~S}$ ribosomal subunit. The signal intensity was quantified by densitometry and expressed as the ratio of VEGF/I8S. The lower panel shows a representative Northern blot analysis of VEGF expression in cell lysates. (B) VEGF expression in the culture medium of D27, D26, D20, M4 and parent C6 cell lines assessed by ELISA. Results are means+s.e.m. of duplicates of three individual experiments (*** $P<0.00$ I compared to control, Student's $t$-test). (C) VEGF secretion in the culture medium of D27 and C6 derived tumours were assessed by ELISA. Results are means+s.e.m. of triplicates of three tumours respectively (*** $P<0.001$, Student's $t$-test). 


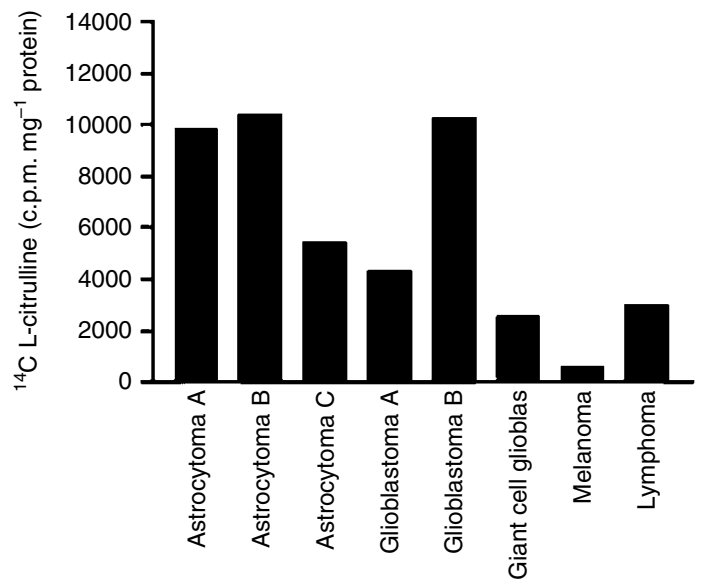

Figure 6 Presence of DDAH activity in human tumours. DDAH activity in tumour homogenates derived from eight individual human tumour biopsy specimens taken during surgical removal of the tumour. DDAH activity was assessed by the conversion of $\left[{ }^{14} \mathrm{C}\right] \mathrm{L}$-NMMA to L-citrulline. DDAH activity varied in the different tumour types.

1997). However, the role of tumour-derived NO is still unclear since overexpression of iNOS in tumour cells can promote or inhibit tumour growth and metastasis (Dong et al, 1994; Jenkins et al, 1995; Xie et al, 1995).

Increased malignancy of human primary brain tumours and the formation of metastasis is associated with increased neovascularisation. Astrocytomas represent one of the most vascularised human neoplasms and the progression from low to high grade is characterised by an increase in neovascularisation, focal necrosis and cellular proliferation. Tumours derived from the rat C6 glioma cell line are histologically classified as astrocytomas and represent a well-established model of human glioblastomas (Barth, 1998). C6 glioma cells express both eNOS and iNOS (Simmons and Murphy, 1993; Barna et al, 1996).

The result of increased DDAH I activity in C6 cells and the concomitant fall in the concentration of ADMA led to a two-fold increase in NO synthesis as observed by increased cGMP production. However this did not alter the in vitro growth properties of the glioma cell lines. The in vivo growth rate of D20, D26 and D27 cells was significantly increased compared to the wild type or the control M4 cells. Our data suggest that DDAH/ADMA pathway does not have a direct effect on the cell cycle or cell proliferation but indirectly affects the tumour growth, possibly by interfering with the tumour vessel development.

To establish a role for ADMA and DDAH in tumour angiogenesis in vivo, MGRE-MRI was used as a non-invasive assay of blood vessel development of D27 and wild type C6 tumours, followed by gross histology and fluorescence microscopy using the nuclear dye Hoechst 33342. It is clear from these experiments that DDAH I expression leads to higher blood volume, better tumour perfusion and increased number of functional vessels. We can therefore speculate that the increased growth observed in D27 tumours is dependent on increased blood vessel development.

Sprouting of endothelial cells from pre-existing vessels, the invasion into the surrounding tissue and the reorganisation into new capillary structures are important steps in vessel development. DDAH I expression and ADMA concentration does not affect the proliferation rate of endothelial cells (V Kostourou, unpublished observations). Therefore, a possible role of DDAH I in vessel development could be the facilitation of the endothelial cell invasion. In support of this, conditioned medium from D27 cells significantly stimulated the migration of SGHEC-7 cells into the fibrin gel compared to medium from C6 or SGHEC-7 cells. These results demonstrate that DDAH activity and the intracellular concentration of ADMA regulate the release of an angiogenic factor or factors in vitro that affect the invasive properties of the endothelial cells.

Vessel growth and development is under the control of a number of factors the most potent being VEGF. VEGF is a largely endothelial cell-specific mitogen that is induced by hypoxia. It promotes angiogenesis, blood vessel permeability and maintains tumour vessel integrity (Shweiki et al, 1992; Yancopoulos et al, 2000). Increased VEGF expression is related to neovascularisation and tumour progression (Takahashi et al, 1995; Zhang et al, 1995) while inhibition of VEGF or its receptors inhibits tumour growth in vivo (Kim et al, 1993; Saleh et al, 1996). Since NO may function as an upstream regulator of expression as well as a downstream effector of the action of VEGF, we examined whether the effects of DDAH and ADMA on tumour angiogenesis were mediated through changes in VEGF. In vitro analysis of VEGF mRNA production as well as VEGF protein secretion in the culture medium demonstrated that DDAH I expression stimulates VEGF production. The increase in VEGF production was similar to that induced by hypoxia in the same cells (V Kostourou, unpublished observations).

Our findings indicate that human tumours exhibit DDAH activity. Although this study is limited in number it does suggest that human brain tumours express particularly high levels of DDAH activity. Increased NO production has also been reported in human CNS tumours (Cobbs et al, 1995). Our experimental data demonstrates that DDAH I can promote tumour growth and increase tumour perfusion. Since tumours with a high grade of malignancy are better perfused and vascularised it is interesting to speculate that DDAH I could facilitate tumour progression and correlate with tumour malignancy. The relationship between DDAH activity and tumour grade is currently under investigation.

In summary, this study shows that increased DDAH expression results in decreased tumour ADMA, increased NO and VEGF production, vascularisation and tumour growth. Our results provide the first demonstration of the importance of the ADMA/ DDAH pathway in the regulation of vessel development. It also has important implications for the regulation of angiogenesis in other pathological and physiological circumstances in which VEGF expression or NO production is involved. The fact that tumour development is so dramatically altered by regulating this pathway adds a novel level of complexity to a system where the precise balance between pro- and anti-angiogenic factors is of key importance. Therapeutic interventions in oncology using the DDAH/ ADMA pathway are therefore plausible.

\section{ACKNOWLEDGEMENTS}

This work was supported by a St. George's Hospital Medical School (SGHMS) studentship to V Kostourou, the Cancer Research Campaign, UK, (CRC) grant SP1971/0404 and the British Heart Foundation (BHF). SP Robinson is the recipient of a Royal Society University Research Fellowship. The authors would like to thank Drs P Wood and J Leiper for helpful early discussions, Dr M Murphy for human tumour biopsies, Professor A Johnstone and JR Griffiths at SGHMS and Professor P. Vallance at UCL for their useful comments on the manuscript, and $\mathrm{Mr} \mathrm{C}$ Brown and his staff for care of the animals. 


\section{REFERENCES}

Barna M, Komatsu T, Reiss CS (1996) Activation of type III nitric oxide synthase in astrocytes following a neurotropic viral infection. Virology 223: $331-343$

Barth RF (1998) Rat brain tumor models in experimental neuro-oncology: the 9L, C6, T9, F98, RG2 (D74), RT-2 and CNS-1 gliomas. J Neurooncol 36: $91-102$

Carmeliet P, Jain RK (2000) Angiogenesis in cancer and other diseases. Nature 407: 249-257

Chin K, Kurashima Y, Ogura T, Tajiri H, Yoshida S, Esumi H (1997) Induction of vascular endothelial growth factor by nitric oxide in human glioblastoma and hepatocellular carcinoma cells. Oncogene 15: 437-442

Chinje EC, Stratford IJ (1997) Role of nitric oxide in growth of solid tumours: a balancing act. Essays Biochem 32: 61-72

Cobbs CS, Brenman JE, Aldape KD, Bredt DS, Israel MA (1995) Expression of nitric oxide synthase in human central nervous system tumors. Cancer Res 55: $727-730$

Dong ZY, Staroselsky AH, Qi XX, Xie KP, Fidler IJ (1994) Inverse correlation between expression of inducible nitric-oxide synthase activity and production of metastasis in K-1735 murine melanoma-cells. Cancer Res 54: $789-$ 793

Fickling SA, Tooze JA, Whitley GS (1992) Characterization of human umbilical vein endothelial-cell lines produced by transfection with the early region of Sv40. Exp Cell Res 201: $517-521$

Fickling SA, Williams D, Vallance P, Nussey SS, Whitley GS (1993) Plasma concentrations of endogenous inhibitor of nitric oxide synthesis in normal pregnancy and pre-eclampsia. Lancet 342: $242-243$

Folkman J (1995) Angiogenesis in cancer, vascular, rheumatoid and other disease. Nature Medicine 1: $27-31$

Fukumura D, Yuan F, Endo M, Jain RK (1997) Role of nitric oxide in tumor microcirculation. Blood flow, vascular permeability, and leukocyteendothelial interactions. Am J Pathol 150: 713-725

Gallo O, Masini E, Morbidelli L, Franchi A, Fini-Storchi I, Vergari WA, Ziche M (1998) Role of nitric oxide in angiogenesis and tumor progression in head and neck cancer. J Natl Cancer Inst 90: 587-596

Griffiths JR, McSheehy PMJ, Robinson SP, Troy H, Chung Y-L, Leek RD, Williams KJ, Stratford IJ, Harris AL, Stubbs M (2002) Metabolic changes detected by in vivo magnetic resonance studies of Hepa-1 wild-type tumours and tumours deficient in hypoxia-inducible-factor-1b: evidence of an anabolic role for the HIF-1 pathway. Cancer Res 62: 688-695

Holden DP, Fickling SA, Whitley GS, Nussey SS (1998) Plasma concentrations of asymmetric dimethylarginine, a natural inhibitor of nitric oxide synthase, in normal pregnancy and preeclampsia. Am J Obstet Gynecol 178: $551-556$

Jang JJ, Ho HK, Kwan HH, Fajardo LF, Cooke JP (2000) Angiogenesis is impaired by hypercholesterolemia: role of asymmetric dimethylarginine. Circulation 102: $1414-1419$

Jenkins DC, Charles IG, Thomsen LL, Moss DW, Holmes LS, Baylis SA, Rhodes P, Westmore K, Emson PC, Moncada S (1995) Roles of nitric oxide in tumor growth. Proc Natl Acad Sci USA 92: 4392-4396

Kakimoto Y, Akazawa S (1970) Isolation and identification of N-G,N-G- and $\mathrm{N}-\mathrm{G}, \mathrm{N}^{\prime}$-G-dimethyl-arginine, N-epsilon-mono-, di-, and trimethyllysine, and glucosylgalactosyl- and galactosyl-delta-hydroxylysine from human urine. J Biol Chem 245: $5751-5758$

Kim KJ, Li B, Winer J, Armanini M, Gillett N, Phillips HS, Ferrara N (1993) Inhibition of vascular endothelial growth factor-induced angiogenesis suppresses tumor-growth in vivo. Nature 362: $841-844$

Kimoto M, Whitley GS, Tsuji H, Ogawa T (1995) Detection of N-G,N-GDimethylarginine dimethylaminohydrolase in human tissues using a monoclonal-antibody. J Biochem 117: $237-238$

Leiper JM, Santa Maria J, Chubb A, MacAllister RJ, Charles IG, Whitley GS, Vallance P (1999) Identification of two human dimethylarginine dimethylaminohydrolases with distinct tissue distributions and homology with microbial arginine deiminases. Biochem J 343: 209-214

MacAllister RJ, Fickling SA, Whitley GS, Vallance P (1994) Metabolism of methylarginines by human vasculature - implications for the regulation of nitric-oxide synthesis. Br J Pharmacol 112: 43-48

MacAllister RJ, Whitley GS, Parry H, Kimoto M, Ogawa T, Hodson H, Moncada S, Vallance P (1996) Regulation of NO synthesis by dimethylarginine dimethylaminohydrolase. Br J Pharmacol 117: P76-P76
Matsuoka H, Itoh S, Kimoto M, Kohno K, Tamai O, Wada Y, Yasukawa H, Iwami G, Okuda S, Imaizumi T (1997) Asymmetrical dimethylarginine, an endogenous nitric oxide synthase inhibitor, in experimental hypertension. Hypertension 29: $242-247$

Miyazaki H, Matsuoka H, Cooke JP, Usui M, Ueda S, Okuda S, Imaizumi T (1999) Endogenous nitric oxide synthase inhibitor - A novel marker of atherosclerosis. Circulation 99: 1141-1146

Nehls V, Drenckhahn D (1995) A novel, microcarrier-based in vitro assay for rapid and reliable quantification of three-dimensional cell migration and angiogenesis. Microvasc Res 50: 311-322

Ogawa T, Kimoto M, Sasaoka K (1989) Purification and properties of a new enzyme, $\mathrm{Ng}$,Ng-dimethylarginine dimethylaminohydrolase, from ratkidney. I Biol Chem 264: 10205-10209

Papapetropoulos A, Garcia-Cardena G, Madri JA, Sessa WC (1997) Nitric oxide production contributes to the angiogenic properties of vascular endothelial growth factor in human endothelial cells. J Clin Invest 100: $3131-3139$

Pipili-Synetos E, Papageorgiou A, Sakkoula E, Sotiropoulou G, Fotsis T, Karakiulakis G, Maragoudakis ME (1995) Inhibition of angiogenesis, tumour growth and metastasis by the NO-releasing vasodilators, isosorbide mononitrate and dinitrate. Br J Pharmacol 116: 1829-1834

Reveneau S, Arnould L, Jolimoy G, Hilpert S, Lejeune P, Saint-Giorgio V, Belichard C, Jeannin JF (1999) Nitric oxide synthase in human breast cancer is associated with tumor grade, proliferation rate, and expression of progesterone receptors. Lab Invest 79: 1215-1225

Robinson SP, Rodrigues LM, Howe FA, Stubbs M, Griffiths JR (2001) Effects of different levels of hypercapnic hyperoxia on tumour $\mathrm{R}_{2}^{*}$ and arterial blood gases. Magnetic Resonance Imaging 19: 161-166

Saleh M, Stacker SA, Wilks AF (1996) Inhibition of growth of C6 glioma cells in vivo by expression of antisense vascular endothelial growth factor sequence. Cancer Res 56: 393-401

Shima DT, Kuroki M, Deutsch U, Ng YS, Adamis AP, D’Amore PA (1996) The mouse gene for vascular endothelial growth factor. Genomic structure, definition of the transcriptional unit, and characterization of transcriptional and post-transcriptional regulatory sequences. J Biol Chem 271: $3877-3883$

Shweiki D, Itin A, Soffer D, Keshet E (1992) Vascular endothelial growthfactor induced by hypoxia may mediate hypoxia-initiated angiogenesis. Nature 359: $843-845$

Simmons ML, Murphy S (1993) Cytokines regulate L-arginine-dependent cyclic-GMP production in rat glial-cells. Eur J Neurosci 5: 825-831

Smith KA, Hill SA, Begg AC, Denekamp J (1988) Validation of the fluorescent dye Hoechst 33342 as a vascular space marker in tumours. $\mathrm{Br} \mathrm{J}$ Cancer 57: $247-253$

Stuehr DJ, Nathan CF (1989) Nitric oxide. A macrophage product responsible for cytostasis and respiratory inhibition in tumor target cells. J Exp Med 169: $1543-1555$

Takahashi Y, Kitadai Y, Bucana CD, Cleary KR, Ellis LM (1995) Expression of vascular endothelial growth-factor and its receptor, $\mathrm{Kdr}$, correlates with vascularity, metastasis, and proliferation of human colon-cancer. Cancer Res 55: $3964-3968$

Thomsen LL, Lawton FG, Knowles RG, Beesley JE, Riverosmoreno V, Moncada S (1994) Nitric-oxide synthase activity in human gynecological cancer. Cancer Res 54: $1352-1354$

Thomsen LL, Scott JMJ, Topley P, Knowles RG, Keerie AJ, Frend AJ (1997) Selective inhibition of inducible nitric oxide synthase inhibits tumor growth in vivo: Studies with 1400W, a novel inhibitor. Cancer Res 57: $3300-3304$

Trachtman H, Futterweit S, Garg P, Reddy K, Singhal PC (1996) Nitric oxide stimulates the activity of a $72-\mathrm{kDa}$ neutral matrix metalloproteinase in cultured rat mesangial cells. Biochem Biophys Res Commun 218: 704-708

Whitley GS (1994) Extraction and assay of cyclic nucleotides. Methods Mol Biol 27: $189-197$

Xie K, Huang S, Dong Z, Juang SH, Gutman M, Xie QW, Nathan C, Fidler IJ (1995) Transfection with the inducible nitric oxide synthase gene suppresses tumorigenicity and abrogates metastasis by K-1735 murine melanoma cells. J Exp Med 181: $1333-1343$ 
Yancopoulos GD, Davis S, Gale NW, Rudge JS, Wiegand SJ, Holash J (2000) Vascular-specific growth factors and blood vessel formation. Nature 407: $242-248$

Zhang HT, Craft P, Scott PA, Ziche M, Weich HA, Harris AL, Bicknell R (1995) Enhancement of tumor growth and vascular density by transfection of vascular endothelial cell growth factor into MCF-7 human breast carcinoma cells. J Natl Cancer Inst 87: 213-219
Ziche M, Morbidelli L, Masini E, Amerini S, Granger HJ, Maggi CA, Geppetti P, Ledda F (1994) Nitric oxide mediates angiogenesis in vivo and endothelial cell growth and migration in vitro promoted by substance P. J Clin Invest 94: $2036-2044$ 